\title{
Las iglesias latinoamericanas en la literatura arquitectónica italiana durante los años del Vaticano II
}

Latin America in the Italian architectural literature during the years of Vatican II

Andrea Longhi · Interuniversity Department of Urban and Regional Studies and Planning. Politécnico di Torino (Italia)

https://doi.org/10.17979/aarc.2015.4.0.5117

\section{RESUMEN}

Si la historiografía ya ha tratado de manera específica las conexiones entre la arquitectura litúrgica italiana y el Movimiento Litúrgico de la Europa Central, las relaciones entre Italia y América Latina están todavía pendientes de estudiar y clarificar. La presente contribución quiere proponer un primer esbozo de investigación, analizando cómo las principales revistas italianas de arquitectura litúrgica (Fede e Arte, editada por el Vaticano, y Chiesa e Quartiere, publicada por la diócesis de Bolonia) presentan la arquitectura cristiana latinoamericana, en relación también con un interés más amplio de otras cabeceras sobre la arquitectura latinoamericana (Casabella, Domus, L'Architettura. Cronache e Storia, etc.). De este primer balance, apoyado en el análisis de cerca de una treintena de articulos y ensayos, emerge una propuesta de cronografía relativa a los años cincuenta y sesenta, hipótesis de trabajo que podrá ser objeto de ulteriores profundizaciones críticas.

\section{PALABRAS CLAVE}

Latinoamérica, literatura arquitectónica, arquitectura religiosa, Italia, Concilio Vaticano II.

\section{ABSTRACT}

If historiography has already specifically studied the links between the Italian liturgical architecture and Liturgical Movement of Central Europe, relations between Italy and Latin America are yet to study and clarify. This contribution wants to propose a first draft of research, analyzing how the main Italian magazines on liturgical architecture (Fede e Arte, published by the Vatican, and Chiesa e Quartiere, published by the diocese of Bologna) show the Christian Latin American architecture, also under broader interest of other headings on Latin American architecture (Casabella, Domus, L'Architettura. Cronache e Storia, etc.). This initial assessment, supported by the analysis of about thirty essais and articles, emerges a proposal of chronography on the fifties and sixties, a working hypothesis that may be subject to further deepening criticism.

\section{KEYWORDS}

Latin America, Architectural Literature, Religious Architecture, Italy, Second Vatican Council. 
La historiografía sobre la arquitectura litúrgica italiana en los años de la espera, preparación y desarrollo del Concilio Vaticano II ya presenta un panorama amplio de referencias culturales extranjeras, ligadas a las experiencias promovidas por el Movimiento Litúrgico en Alemania, Austria, Francia y Bélgica'. El conocimiento de las iglesias innovadoras del centro de Europa se difundió en la Italia de los años cincuenta por medio de algunas revistas y publicaciones especializadas, pero los episodios biográficos (conferencias, viajes, encuentros, etc.) jugaron un rol decisivo, incluso más relevante que la propia difusión editorial. En este cuadro de relaciones interpersonales, el Concilio Vaticano II (1962/65) tuvo un papel fundamental, propiciando que las principales experiencias espaciales europeas - ya en parte conocidas - fueran difundidas y se continuasen (Gabetti 2000, 39).

Para la cultura italiana, el Concilio fue - sobre todo- el momento del descubrimiento de la catolicidad de la Iglesia, es decir, de su dimensión mundial, si bien los representantes extra-europeos fueran un numero todavía relativamente pequeño ${ }^{2}$. Las comunidades italianas perdieron la sensación de su propia centralidad y afrontaron el conocimiento de los dramas y las esperanzas de los otros continentes, cuya evocación fue recogida al comienzo de la constitución pastoral Gaudium et Spes (1965).

\section{EL CONTEXTO DE LA INVESTIGACIÓN Y LAS FUENTES CONSULTADAS}

En esta superación del eurocentrismo se inserta también una nueva mirada hacia la América Latina, continente católico hasta ahora considerado superficialmente como tierra de emigrantes italianos o de misioneros europeos, cuyas expresiones arquitectónicas habían tenido poco espacio en las publicaciones eclesiales. A nosotros aquí nos interesará no tanto la contribución italiana a la cultura latinoamericana, sino viceversa - las sugerencias latinoamericanas que condicionaron la cultura arquitectónica italiana, ya sea de manera directa (ejemplos construidos, proyectos publicados pero no realizados), ya sea de modo indirecto (debates sobre la riqueza y la pobreza en la Iglesia, sobre el marxismo y el cristianismo, etc.). La presente contribución debe, por tanto, en primer lugar colmatar una zona gris en la historiografía sobre la arquitectura litúrgica italiana, en la cual todavía se evidencian dos fenómenos: por un lado, el aprecio por la audacia formal y estructural de algunas iglesias icónicas latinoamericanas de los años cincuenta (obras de Félix Candela, sobre todo, y la precedente iglesia de Niemeyer en Pampulha); y de otro, la relevancia dada en el postconcilio a los problemas sociales y urbanísticos latinoamericanos, espejo de las contradicciones planetarias y de las injusticias perpetradas por diversos regímenes.

Las fuentes históricas utilizadas en la presente comunicación son, sobre todo, las revistas dedicadas a la arquitectura litúrgica: Chiesa e Quartiere (1955/68) y Fede e Arte (1953/67); una tercera revista, la muy prestigiosa Arte Cristiana, manifiesta un modesto interés hacia la arquitectura moderna y ninguna documentación extra-europea; otras publicaciones locales tienen una circulación y un radio de intereses más acotados.

Fede e Arte (Fe y Arte) se editó desde 1953 para animar el debate sobre la reconstrucción de las iglesias destruidas en Italia durante la Segunda Guerra Mundial; se trata, en rigor, de un órgano vaticano, no italiano, pero de hecho el ente promotor - la Pontificia Comisión Central para el Arte Sacro (PCCASI) - tiene competencias institucionales sobre el territorio italiano, en ausencia de una Conferencia Episcopal activa sobre el país (Chenis 2002; De Marchis 2013). La línea cultural de la revista fue dada por el magisterio de Pío XII, pero asumió progresivamente tonos y temas de inspiración montiniana, sobre todo gracias a mons. Giovanni Fallani (1910/85), estudioso de la literatura medieval, presidente de la PCCASI de 1956 a 1985 (Bracco 1994; De Marchis 2013, 72ss). La revista dedica una espacio amplio a las experiencias ligadas con el Movimiento Litúrgico en Europa, pero son interesantes las aspiraciones de mundialización y de inculturación que sostiene - sobre todo desde una perspectiva asiática y misionera - gracias a los cardenales Celso y Giovanni Costantini (Longhi 2010; Pighin 2015). Es incluso significativo que en la síntesis histórico-geográfica más amplia propuesta por la revista en 1966 (Alfano 1966), el secretario de la comisión (mons. Mario Alfano) describa la arquitectura litúrgica de Italia, Francia, Alemania, Suiza, Austria, Holanda, España y los Estados Unidos, para luego pasar directamente a los países de misión, omitiendo todas las experiencias de países católicos no europeos. América Latina es ignorada completamente. La revista dejó de publicarse en 


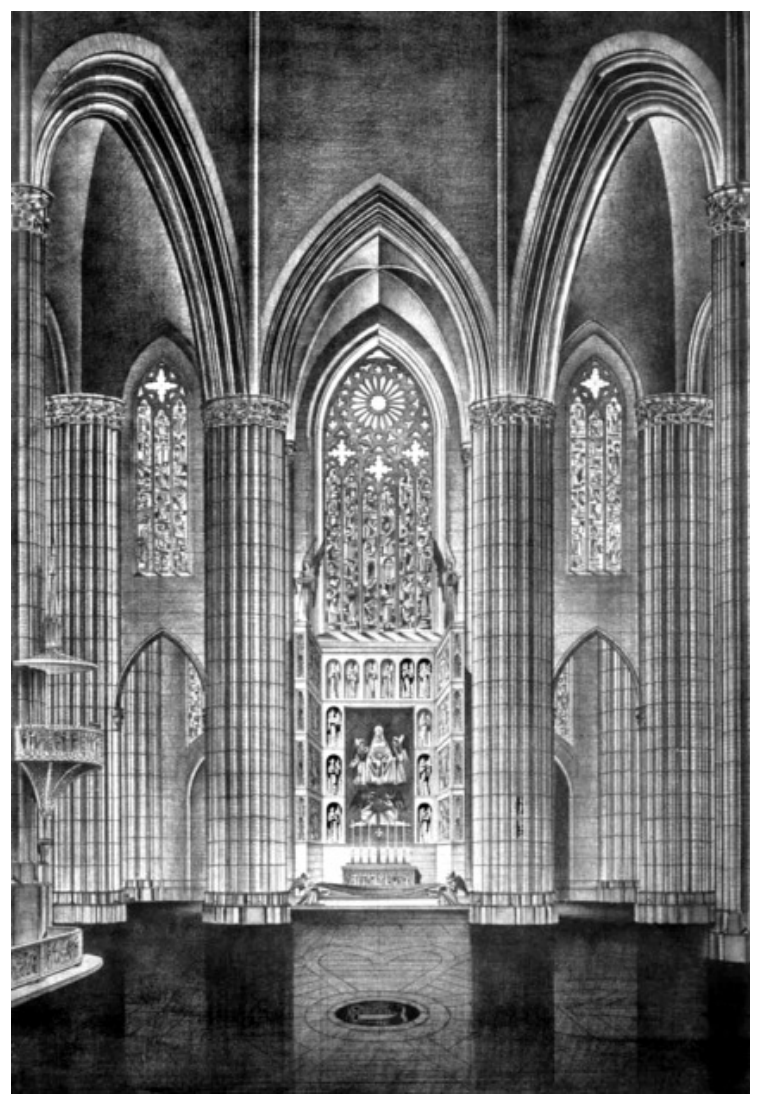

Fig. 01. Bruno Apollonj-Ghetti (coord.), proyecto de adecuación litúrgica de la Catedral Metropolitana de Sâo Paulo (Brasil), 1950/53.

Proyecto de preparación del crucero y de los altares del transepto (a), maqueta de ciborio sobre el altar (b) y de la capilla del Santísimo (c), con esculturas de Francesco Nagni. Fede e Arte 3/53 (1953).
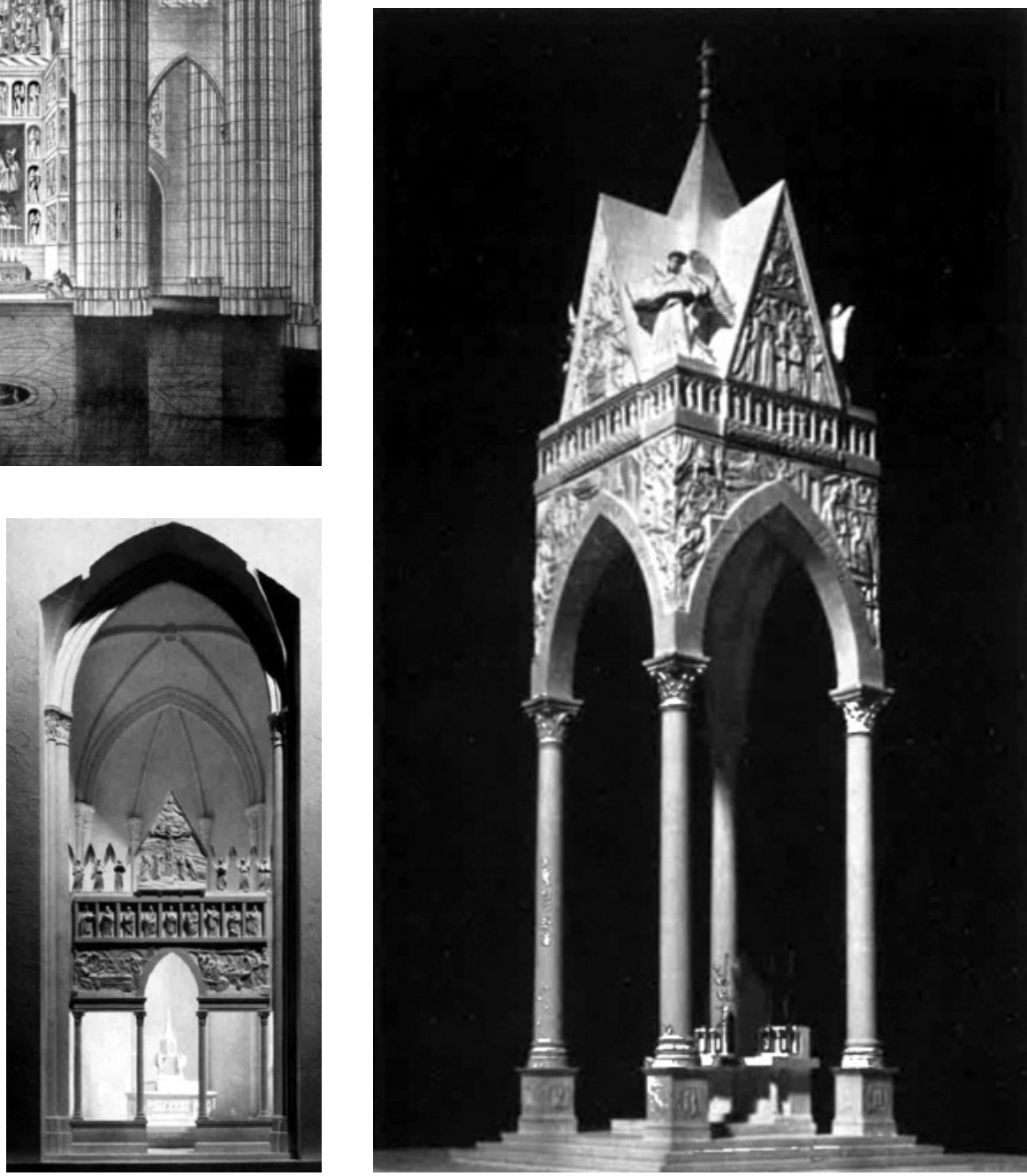
1967, porque la reconstrucción postbélica ya se había terminado pero, sobre todo, porque los desafíos conciliares y mundiales iban mucho más allá de la dimensión italiana de la revista.

Chiesa e Quartiere (Iglesia y barrio) es la expresión del laboratorio boloñés promovido en 1955 por el cardenal Giacomo Lercaro -arzobispo de Bolonia de 1952 a 1968 - para establecer un vínculo entre la arquitectura eclesial y el Movimiento Moderno, con dos puntos de atención: la preeminencia de los temas litúrgicos respecto a los formales, y una intensa sensibilidad social hacia los problemas de las periferias (Gresleri, Bettazzi y Gresleri 2004; Manenti 2010; Fernández-Cobián 2013). El laboratorio se convierte en el centro de animación arquitectónica más vivo en la Italia del Concilio, pero se disuelve en 1968 tras la dimisión forzada del cardenal Lercaro y de la normalización sociopolítica de su episcopado de frontera (Gresleri 1990). Precisamente el último número de la revista (46/47, junio-septiembre 1968), marca el fin de nuestra investigación: completamente dedicado a los temas sociales y políticos latinoamericanos, la revista acaba por no ocuparse ya más de arquitectura litúrgica, considerada — de hecho- un tema marginal - $\mathrm{O}$ peor- que distrae respecto de las emergencias reales.

La difusión de las experiencias latinoamericanas en las revistas italianas estuvo enmarcada en cuatro escenarios.

A. Arquitectura litúrgica e instituciones: el caso brasileño presentado por Fede e Arte durante los años cincuenta.

B. Arquitectura litúrgica y experimentación formal: la desconfianza de Chiesa e Quartiere.

C. ¿Monumentalismo y/o experimentación pastoral? Contrastes y búsquedas al final del Concilio.

D. La autoanulacion del debate arquitectónico en la comunidad cristiana.

\section{A. ARQUITECTURA LITÚRGICA E INSTITUCIONES: EL CASO BRASILEÑO DURANTE LOS AÑOS CINCUENTA}

La revista vaticana Fede e Arte, en sus primeros tres años de publicación, concentró toda su rara atención latinoamericana sobre Brasil, de cuya producción artística aparecen documentados, sobre todo, los desarrollos institucionales, más que formales. El punto de partida es la terminación de la catedral neogótica de Sâo Paulo
(Il riattamento 1953), comenzada en 1912 en la ciudad antigua, bajo el proyecto neogótico del arquitecto alemán (pero residente en Sâo Paulo) Maximilian Hell, de confesión protestante, que configura un enorme edificio de más de $110 \mathrm{~m}$. de largo, cuya cúpula se eleva a $65 \mathrm{~m}$. de altura. Estando la obra incompleta, sobre todo la parte litúrgica, los trabajos se reanudan en 1946 por mons. Carlos Carmelo de Vasconcellos Motta, arzobispo de Sâo Paulo (1944/64), elevado a la púrpura cardenalicia en el mismo año 1946. La iniciativa se gestiona a través de la Legiao pro Catedral de Sâo Paulo, presidida por Olga de Paiva Meira, con el asesoramiento artístico de Renata Crispi da Silva Prado.

La revista, tras una invitación del cardenal Giovanni Costantini a no repetir los modelos artísticos del pasa$\mathrm{do}^{4}$, presenta el proyecto de adecuación litúrgica preparado por Bruno Apollonj-Ghetti (Fig. 01), académico muy cercano a los ambientes romanos y vaticanos (Longhi y Tosco 2010, 6 y 163ss). El proyecto ubica la sacristía y la capilla del Santísimo Sacramento en el primero de los dos deambulatorios, el conjunto de altar, cátedra y asientos en el presbiterio, los dos púlpitos en los dos pilares del crucero, los altares en el transepto dedicados a los dos patronos (santa Ana y san Pablo), y el baptisterio. El programa iconográfico es dictado por el teólogo padre Ermanno Cambié, de los sacerdotes del Santísimo Sacramento. Se trata, evidentemente, de una operación de sabor tardo-colonialista, no privada de ambigüedad incluso en el procedimiento de los encargos profesionales (Apollonj-Ghetti será forzado a precisar su propio papel dos números de la revista más $\operatorname{tarde}^{5}$ (Notiziario 1953: 155): los once artistas invitados son italianos o activos en Italia ${ }^{6}$, las obras son realizadas en Italia y enviadas —ya terminadas - a Sâo Paulo. La iniciativa, todavía, aparece subrayada como ejemplar y replicable en el momento de la fundación del Istituto Internazionale di Arte Liturgica en 1955 (Istituto 1955; Longhi y Tosco 2010, 165).

Casi para compensar este enfoque eurocéntrico, la revista ofrece un amplio espacio editorial al vicepresidente de la Sociedade Brasileira de Arte Cristà, el pintor y grabador Carlos Oswald (1882-1971), nacido en Florencia, que había colaborado en la concepción del Cristo Redentor en el cerro del Corcovado de Río de Janeiro. Oswald ilustra el rol institucional de la Sociedade, inspirada por el cardenal Jaime de Barros Câmara (arzobispo de Río desde 1946 y participante 


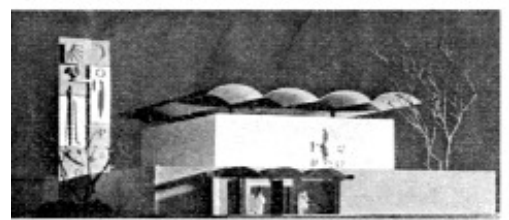

II nuovo centro civico e la chiesa di Puerto Ordaz.

Larehitetto Joes Inix Rert ha giruge.

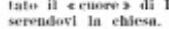

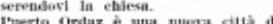
Venexiela. e I.iturziral Arts; bel min. mero dedleate a Blasille. Hong Kond. Venezucla, ne forniste tma complet
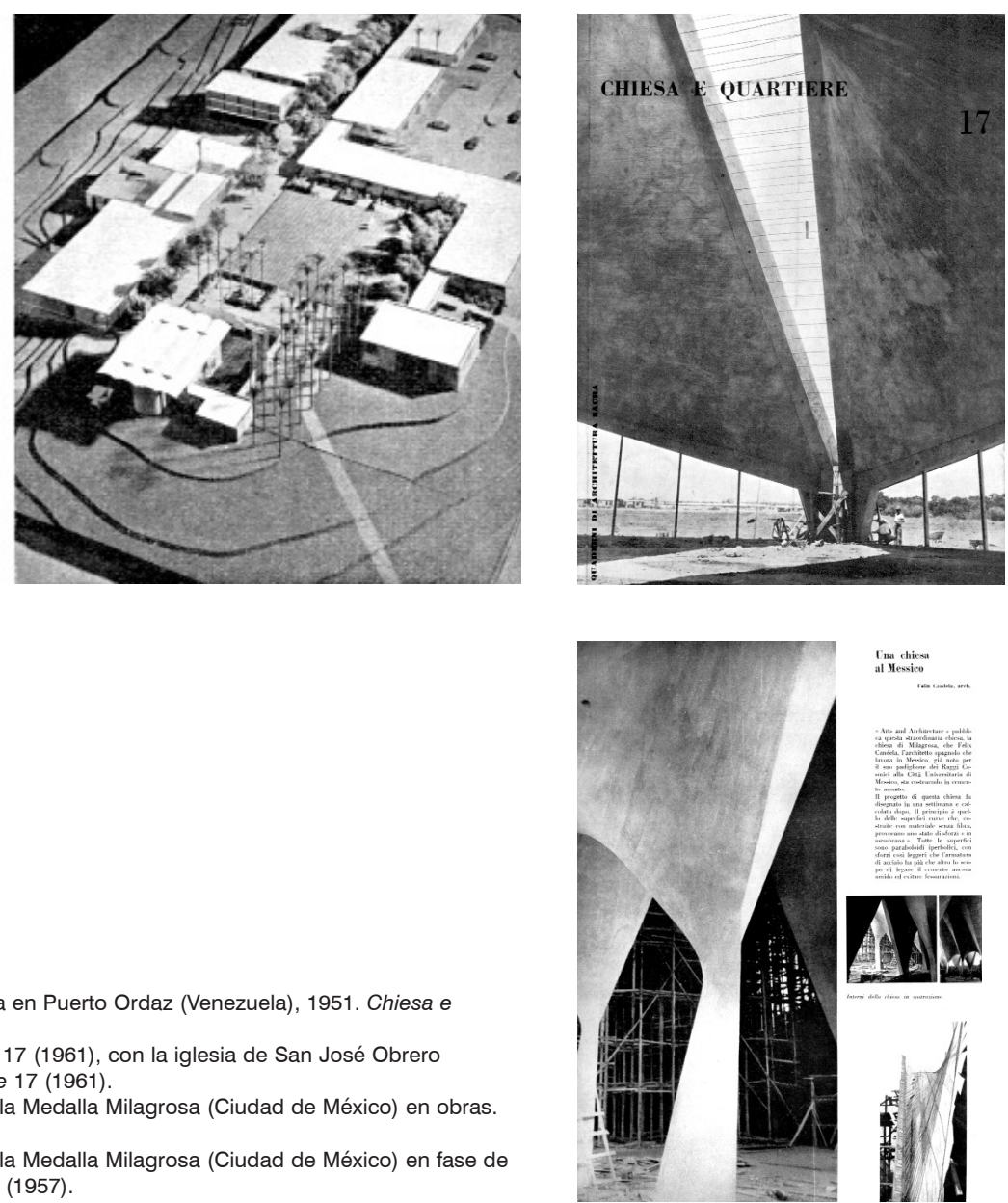

Tnu chicsu
al Mesico

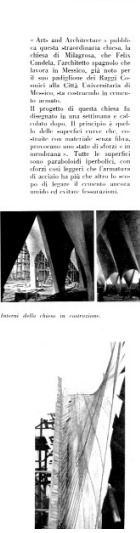

Fig. 02. José Luis Sert, proyecto para una iglesia en Puerto Ordaz (Venezuela), 1951. Chiesa e Quartiere 6 (1958)

Fig. 03. Portada de la revista Chiesa e Quartiere 17 (1961), con la iglesia de San José Obrero (Monterrey, México) en obras. Chiesa e Quartiere 17 (1961).

Fig. 04. Félix Candela, la iglesia de la Virgen de la Medalla Milagrosa (Ciudad de México) en obras. Domus 308 (1955).

Fig. 05. Félix Candela, la iglesia de la Virgen de la Medalla Milagrosa (Ciudad de México) en fase de terminación. L'Architettura. Cronache e Storia 16 (1957).
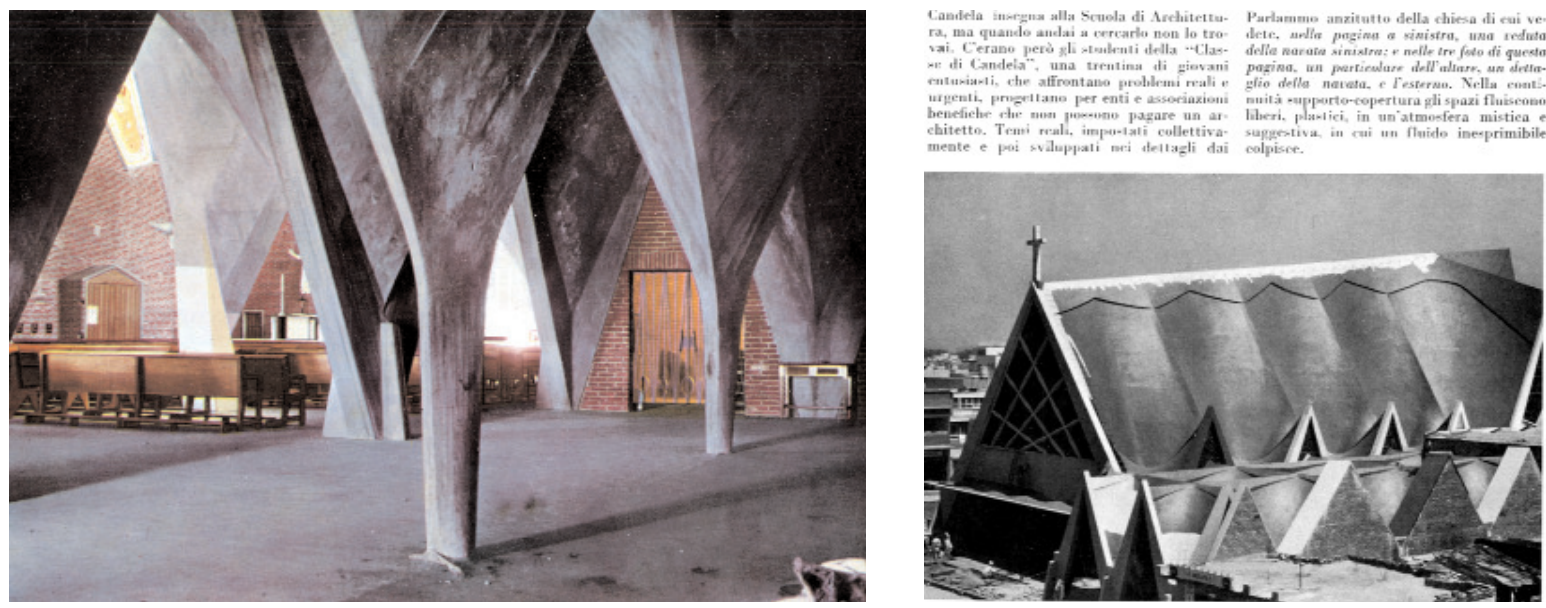
luego en el Concilio) y la iniciativa de la Exposición Internacional de Arte Sacro (Oswald 1953). En 1954 Oswald presenta un amplio y documentado panorama del arte cristiano contemporáneo en Brasil y una recensión - ya publicada en la revista Vozes de Petròpolisdel volumen Fede e Arte del cardenal Celso Costantini (Oswald 1954a; Oswald 1954b).

El enfoque institucional aparece coronado por la publicación en 1959 de la carta pastoral del cardenal Jaime Câmara sobre arte litúrgico —es decir, el arte reservado al servicio del culto, distinguiéndose así del arte religioso y del arte sacro-. Llena de referencias al magisterio pontificio y a la controvertida Instrucción del Santo Oficio de 1952, la carta está abierta a la experimentación, pero sólo si está orientada a la liturgia y a la sacralidad.

En las páginas de información aparecen noticias recogidas de la revista Hábitat — frescos de Cándido Portinari en la iglesia de Batatais ${ }^{7}$ (Rassegna 1953) - y de Das Münster ${ }^{8}$ (Notiziario 1959). En 1954 se presenta una recopilación de noticias sudamericanas, «Notiziario sudamericano» - la única vez en la historia de la revista-: reseñas de exposiciones, concursos, proyectos y publicaciones en Argentina, Bolivia, Cuba y Uruguay.

Dos signos interesantes de un enfoque menos institucionalizado y más litúrgico provienen, sin embargo, del Notiziario estero (Noticiario extranjero) de 1955, preparado por Renzo U. Montini. El crítico señala que en una localidad perdida del norte de Brasil, Villa Cazoni, el misionero italiano Mario del Sante ha construido en un mes una humildísima iglesia, con gusto reseñada «en esta sección en la cual se habla de grandiosas catedrales, formulando votos para que ella constituya la semilla de una gran cristiandad; porque no es la grandeza de las proporciones o la riqueza decorativa lo que constituye la gloria de una iglesia, sino la presencia sobre su altar - por rico o modesto que sea- de Jesús Eucaristía»" (Montini 1955b).

Dos meses después encontramos una sintética aunque equilibrada anotación sobre la iglesia de Pampulha, primera obra religiosa de Óscar Niemeyer (1943), verdadero y proprio icono de la arquitectura religiosa latinoamericana ya conocida en las publicaciones internacionales por su originalidad gestual. La revista no se centra en sus valores formales, sino en la negativa del obispo de Belo Horizonte a consagrarla por la audacia de sus formas constructivas y de las pinturas que la adornan (de Cándido Portinari); pero, frente a la consecuente solicitud de demolición anunciada por el alcalde, el Gobierno salva la obra declarándola Monumento Nacional. La posición vaticana es la siguiente: «La iglesia en cuestión, en cuanto no es una obra de arte sacro, no puede acoger el Sacramento del Altar ni ser abierta al culto; y sapientísima ha sido la decisión del Obispo de no consagrarla. Pero porque es, indudablemente, una obra de arte, el Gobierno brasileño ha hecho muy bien en salvarla del vandalismo indiscriminado del Alcalde $»^{10}$ (Montini 1955a, 314). El crítico se pregunta por qué no se ha hecho lo mismo con las capilla de Vence y de Ronchamp, excelentes arquitecturas y pésimas iglesias. La iglesia de Pampulha será consagrada en 1959 y se mantendrá ignorada por las publicaciones católicas, aunque mitificada por la literatura arquitectónica.

\section{B. ARQUITECTURA LITÚRGICA Y EXPERIMEN- TACIÓN FORMAL: LA DESCONFIANZA DE CHIESA E QUARTIERE}

Durante los años cincuenta, la revista Chiesa $e$ Quartiere concentra su atención sobre proyectos y temas italianos y europeos; con respecto a América Latina, señala sólo el proyecto de José Luis Sert para una iglesia en la nueva ciudad de Puerto Ordaz (Venezuela), nunca realizada. La noticia fue recogida de Liturgical Arts (Il nuovo centro civico 1958). La iglesia había sido proyectada en 1951 por encargo de la Orinoco Mining Company (Freixa 1979; Rovira 2000) (Fig. 02).

En toda la historia de la revista solo existe un artículo que se concentra monográficamente sobre las iglesias latinoamericanas: se trata del dossier de 1961 (Fig. 03), preparado por Tudy Sammartini, sobre cuatro iglesias de Enrique de la Mora y Palomar, conocidas sobre todo por sus estructuras de Félix Candela, de las cuales ya habían sido reseñadas por las revistas laicas la Virgen de la Medalla Milagrosa — publicada por Domus en 1955 y L'Architettura. Cronache e Storia, en 1957 (Fig. 0405) - y San Vicente de Paúl en Coyoacán — por Casabella en 1959 (Una chiesa 1955; Nicoletti 1957; Strutture 1959)" (Fig. 06) - mientras las obras todavía estaban en marcha. Estas revistas habían informado sobre el tema de la estructura, más que sobre el aspecto formal definitivo; y lo litúrgico no les interesaba nada.

La redacción consideró necesario un largo Preámbulo con el que intentar justificar el retraso con 

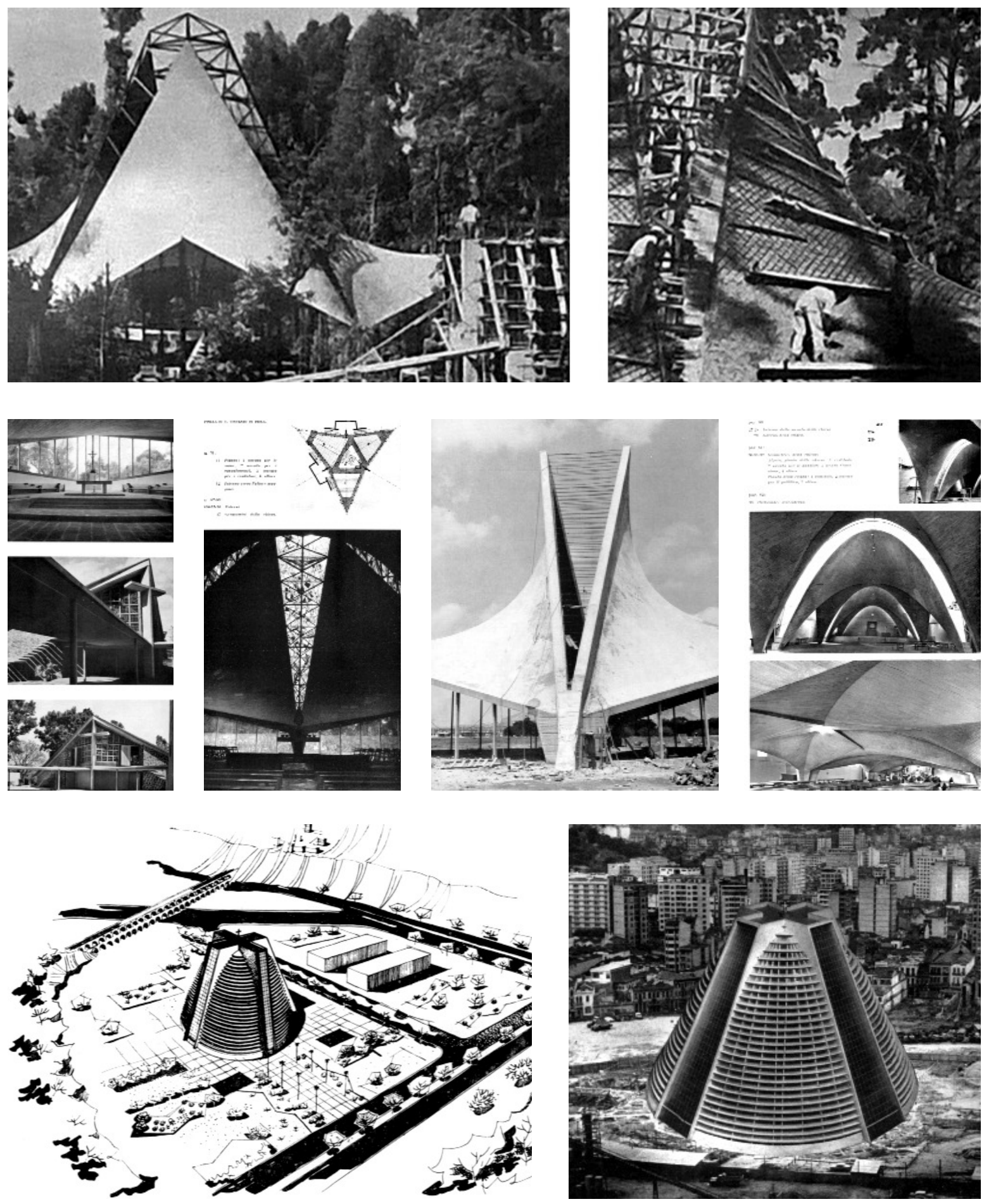
En la página anterior:

Fig. 06. Enrique de la Mora, Fernando López Carmona y Félix Candela, iglesia de San Vicente de Paúl (Coyoacán, Ciudad de México). Casabella 232 (1959)

Fig. 07. Imágenes del reportaje de Chiesa e Quartiere 17 (1961) sobre cuatro iglesias de Enrique de la Mora, Fernando López Carmona y Félix Candela: Nuestra Señora de la Soledad del Altillo (a) y San Vicente de Paúl (b) en Coyoacán (Ciudad de México), San José Obrero (c) en Monterrey y San Antonio de las Huertas (d) en Tlaxpana (Ciudad de México).

Fig. 08. Edgar de Oliveira da Fonseca, Catedral Metropolitana de Sâo Sebastiâo, Río de Janeiro (Brasil), 1964/76. (a) Boceto volumétrico preparatorio; (b) fotomontaje del proyecto. Fede e Arte 1/66 (1966)

En esta página:

(c) Ceremonia de la bendición de la primera piedra, 20 de enero de 1964. Fede e Arte 1/66 (1966).

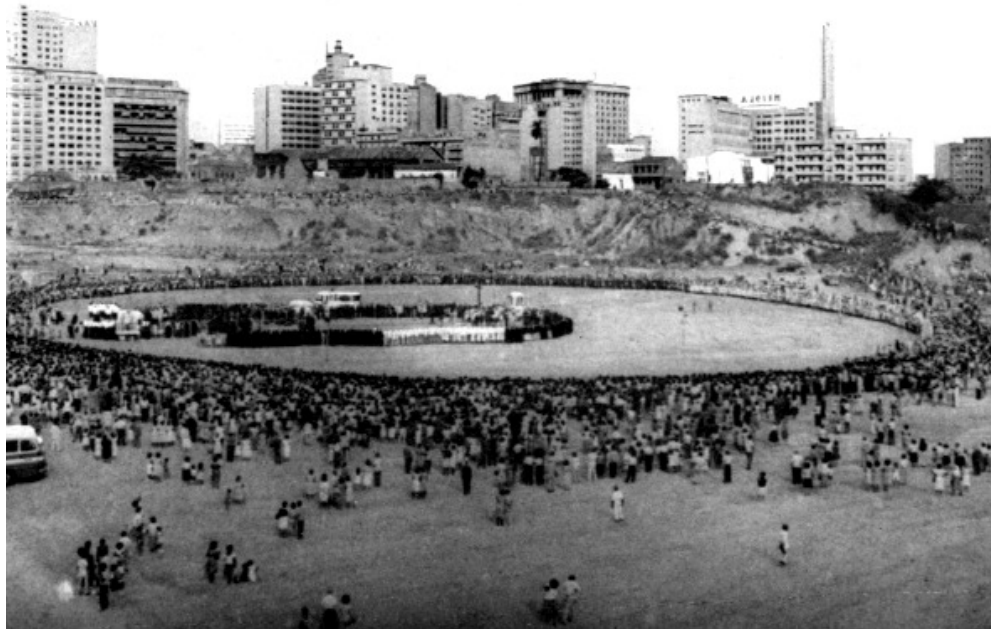

el que la revista presentaba iglesias ya muy conocidas por sus arriesgadas estructuras, pero sobre todo, destinado a defender los principios inspiradores de la revista. De hecho, es evidente su incomodidad al reconocer interés y calidad en edificios que tratan temas religiosos con un enfoque no directamente inspirado en la liturgia ni en temas socio-urbanísticos. Según la redacción, «un espacio sagrado del tipo de los que estamos considerando, verificado en la atmósfera mística que es capaz de proponer, en su estructura orgánica y eficiencia litúrgica, en las reflexiones que es capaz de proporcionar, podría revelar los límites de ciertas soluciones», las cuales se basan únicamente en una «investigación que podríamos definir en gran medida como geométricoestructural». El resultado es que - a causa de su «no relación con el tejido urbano»-, estas soluciones pueden ser apropiadas sólo en "contextos naturales» (Redazione 1961, 38). Para la autora, que ha visitado y fotografiado directamente los cuatro edificios (Fig. 07), «en lugar de partir de la función para crear la arquitectura, el arquitecto De la Mora parece, al contrario, partir de volúmenes en los cuales ha inscrito las diferentes actividades previstas por el programa de una iglesia. Disociando la forma de la función, De la Mora parece caer en un manierismo, es decir, parece dedicarse más a la búsqueda de formas sorprendentes que convincentes $»^{12}$ (Sammartini 1961, 40). Por otra parte, «ciertas formas curvilíneas son interesantes, pero se acercan a una obsesión maníaca: son simbolismo, y no el resultado de un volumen nacido de la experiencia de un ser como usuario» ${ }^{13}$ (Sammartini 1961, 42).

Después de esta concesión a las iglesias de moda, conocidas por sus cualidades expresivas no eclesiales, Chiesa e Quartiere no volverá más sobre cuestiones latinoamericanas hasta la aparición de los problemas políticos y sociales en el postconcilio, documentados por la reforma de la revista en marzo de 1965.

\section{C. ¿MONUMENTALISMO Y/O EXPERIMENTACIÓN PASTORAL? CONTRASTES Y BÚSQUEDA AL FINAL DEL CONCILIO}

En Fede e Arte, a comienzos de 1965 - es decir, tras la aprobación de la constitución sobre la liturgia Sacrosanctum Concilium, pero antes de la elaboración final de la constitución pastoral Gaudium et Spes-, el editorialista anónimo Itálicus afronta abiertamente el tema de la sobriedad reclamada por los padres conciliares, que «no pueden autorizar a nadie a considerar cerrado el capítulo de la arquitectura sacra monumental». De hecho, «no ha existido ninguna condena y no ha habido, por parte de la Iglesia, ninguna sugerencia para considerarla como una manifestación exclusiva del pasado». Brasil es elegido como emblema de las contradicciones. Por una parte, se elogia al obispo que ha aplazado la 


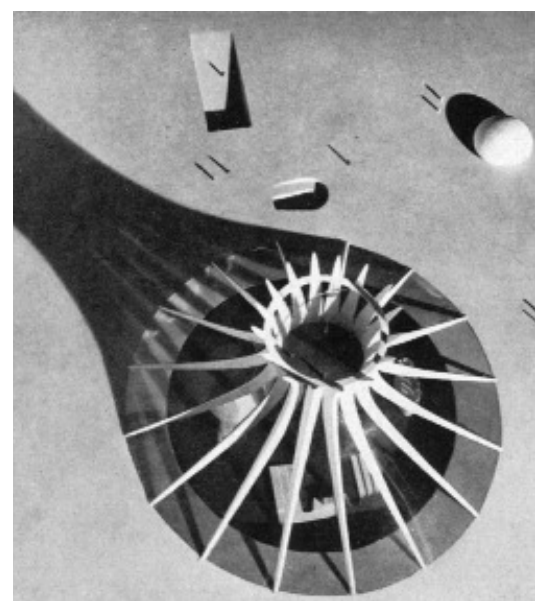

\section{L'APARECIDA}

$\mathrm{Ci}$ viene segnalato dal Brasile il completamento dei lavori alla basilica della Aparecida, sorta sul luogo ove alcuni indigeni erano soliti recarsi a pregare dinanzi ad una statuetta della Vergine trovata nel fiume.

Cosa si è costruito all'Aparecida? Una chiesa al cui confronto impallidiscono per altezza le strutture delle terme di Diocleziano, affiancata da una torre in cemento armato alta $60 \mathrm{~m} . !$ (Ignoriamo le qualità, la quantità dei «marmi » che certamente completeranno l'insieme). Non intendiamo né polemizzare, né criticare un discorso che non può neppure lontanamente essere preso in considerazione e chiamato architettura. Ci sia consentito di essere scandalizzati di questa testimonianza, tra uomini poveri e semplici, le cui abitazion: scao, nell'anno 2000, di fango e di paglia.

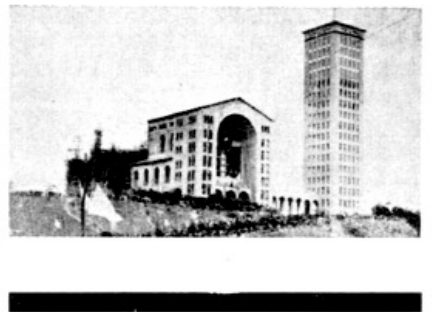

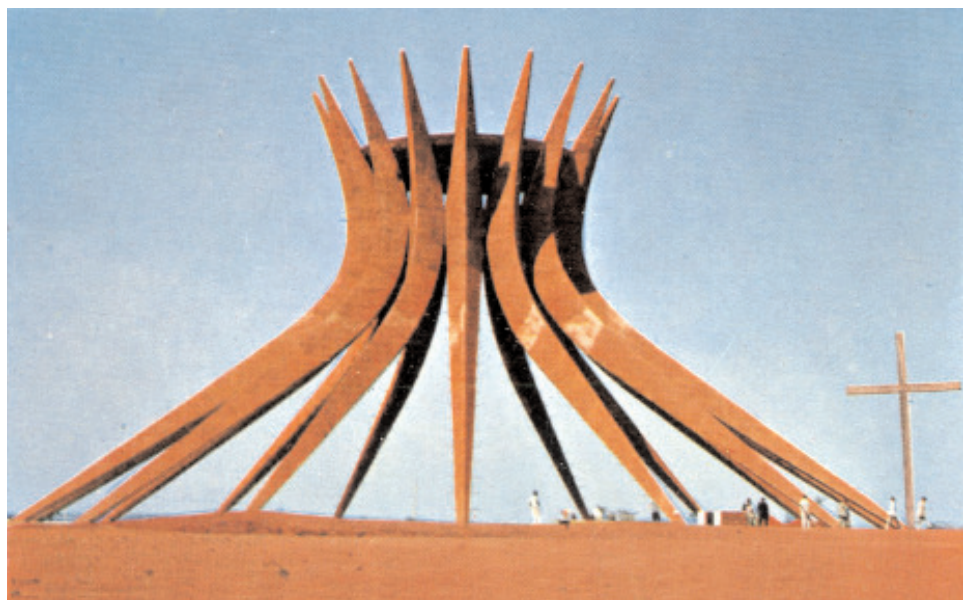

Fig. 09. Oscar Niemeyer, Catedral Metropolitana de Nossa Senhora Aparecida, Brasilia (Brasil), 1958/70. La construcción de la catedral está documentada en la literatura arquitectónica: (a) la maqueta en L'Architettura. Cronache e storia 51 (1960); (b) las obras en Domus 434 (1966)

Fig. 10. Benedito Calixto Neto, Santuario Nacional de Nossa Senhora da Conceição Aparecida (Brasil), 1946/80. Artículo de Chiesa e Quartiere 43 (1967) que comenta las obras de la basílica.

Fig. 11. Portada del número 46/47 (1968) de la revista Chiesa e Quartiere, dedicado por completo a Latinoamérica. Fue el último número.

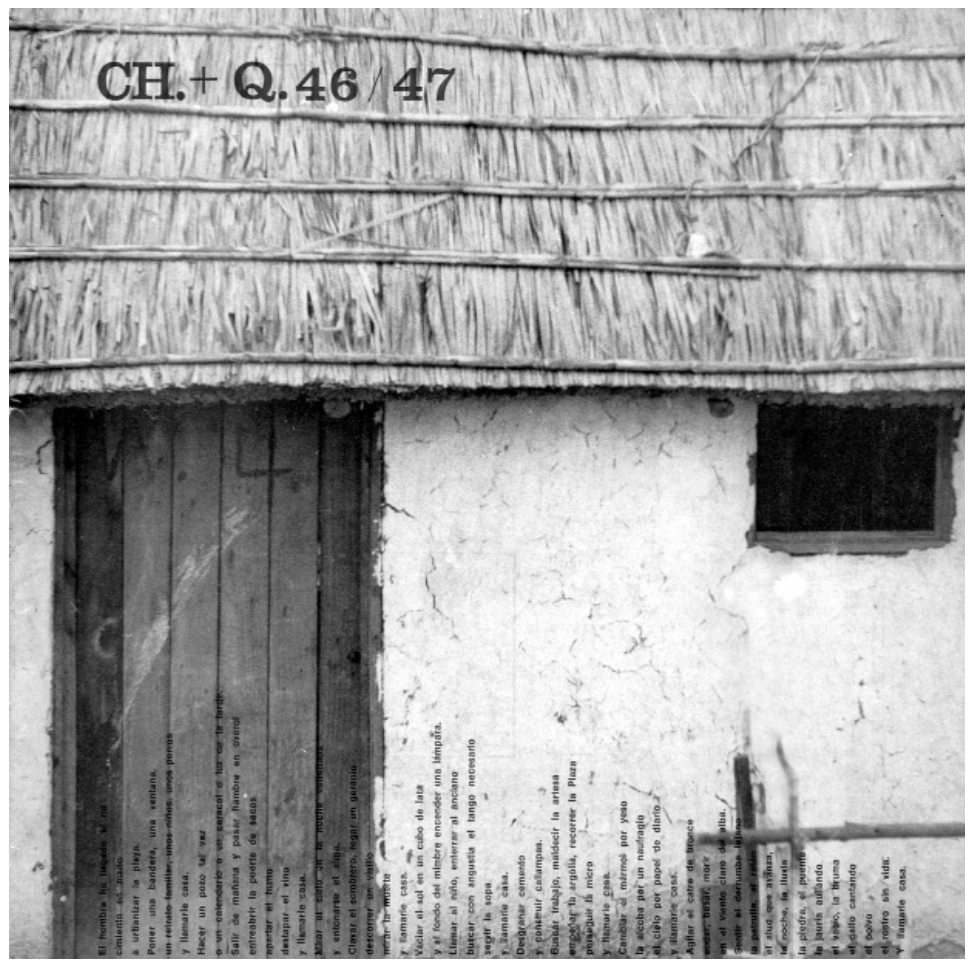


construcción de una catedral, ya que «en algunas circunstancias, se rinde más honor a Dios con la caridad y con las iglesias provisionales que con suntuosos edificios de culto». Pero también se salvaguarda la opción monumental/representativa, ya que el ejemplo de la pobreza «no sería válido si se pretendiese que en Brasilia no se construyera una catedral digna de aquella nueva y espléndida capital» ${ }^{14}$ (Italicus 1965, 100).

La opinión de Chiesa e Quartiere es opuesta. En marzo de 1966, con el Concilio ya terminado, Glauco Gresleri escribe: «No tenemos ninguna necesidad de nuevas formas arquitectónicas, ni de nuevas 'soluciones' [...] En la actualidad no existe tanto el problema de una arquitectura sacra como el problema de una visión cristiana de la arquitectura y el papel que ésta juega en la sociedad moderna $\rangle^{15}$ (Gresleri 1966: 8).

Las dos líneas editoriales se separan.

Fede e Arte publica el proyecto de la enorme catedral de Río de Janeiro (La cattedrale 1966), de Edgar de Oliveira da Fonseca, comenzada en 1964 sobre una planta circular superpuesta a una cruz griega, con unas dimensiones de 110 metros de diámetro y 80 metros de altura, y una capacidad para doce mil fieles ${ }^{16}$ (Fig. 08). Es interesante la elección crítica hecha por la revista: aunque bien conocida, no aparece publicada la famosísima catedral de Brasilia, entonces en construcción, sino otra catedral brasileña nueva, de mayor interés eclesial. Menos convincente desde el punto de vista formal e ignorada por la literatura especializada italiana, la catedral carioca es el éxito de una profunda reflexión compartida con el comitente, el cardenal Jorge Câmara, a diferencia de la operación estatal y laica de Brasilia. En Río, la opción monumental parece, por tanto, motivada por un razonamiento teológico y eclesial, fundado sobre todo sobre el tema explícitamente cristocéntrico (La cattedrale 1966: 67). La catedral de Brasilia inconclusa durante muchos años - en toda la literatura arquitectónica y urbanística publicada en Italia durante los años sesenta (Inchiesta 1960; Papadaki 1961; Casati 1966; Bracco 1967; Bullrich 1970; Spade 1971) aparecerá ilustrada primero con la maqueta, y luego con fotos de una metafísica estructura vacía, privada de referencias a la vida religiosa de la nueva capital (Fig. 09).

Chiesa e Quartiere elige, por el contrario, el tema de la comunidad. Describe por dos veces la experiencia de la parroquia de Cristo Redentor en la barriada de San Miguelito, en Panamá City (Fitzpatrick 1966; Bravo
1967), lugar de experimentación pastoral de fama mundial pero carente de cualquier relevancia de tipo arquitectónico. Para la redacción de la revista, es la comunidad - y no la arquitectura - la que construye el lugar. En el Notiziario, aparece reseñado polémicamente el fin de las obras de la basílica de Aparecida (Fig. 10): «No pretendemos ni polemizar ni criticar un discurso que no puede, ni siquiera lejanamente, ser tomado en consideración ni ser llamado arquitectura. Esperamos que se nos permita escandalizarnos por este testimonio, [levantado] entre hombres pobres y sencillos, cuyas viviendas son, en el año 2000, de barro y de paja» (L'Aparecida 1967, 65) ${ }^{17}$.

\section{LA AUTOANULACION DEL DEBATE ARQUI- TECTONICO EN LA COMUNIDAD CRISTIANA}

Con un artículo de Paolo Caruso de 1967, Chiesa e Quartiere pone su atención sobre el racismo, el colonialismo y los genocidios perpetrados por los europeos en América Latina. Tras una serie de cartas de lectores afectados por el tema, dos números después del artículo de Caruso el tema se vuelve a abrir, refiriéndose también a la actividad de la Comisión Figueredo de las Naciones Unidas sobre el trato de los colonizadores hacia las comunidades indígenas brasileñas. El momento para la revista es difícil: en el mismo número 45 aparece anunciada la renuncia del obispo Lercaro, promotor y organizador del debate arquitectónico, litúrgico y social sobre el que se apoya la revista; un artículo sobre la sociología de las parroquias de Bolonia es, de hecho, censurado.

Justo con el número doble 46/47 sobre América Latina (Fig. 11), totalmente privado de referencias a la arquitectura de iglesias, se termina la vida de la revista en el otoño de 1968, en el ápice de las revueltas estudiantiles y obreras en Europa. Las comunidades cristianas italianas son radicalmente interpeladas y laceradas por el debate sobre la relación entre cristianismo y marxismo, entre solidaridad y capitalismo, entre riqueza y pobreza.

Si la evidente alineación política de la revista molesta al nuevo obispo - enviado desde la Curia romana a normalizar el debate cultural boloñés - y determina su cierre, se debe señalar que la crisis de la misma es también $-\mathrm{y}$ sobre todo- epistemológica. La redacción considera que ha llegado el momento de dejar de ocuparse de la arquitectura para pasar al trabajo social directo. El editorial de Giuliano Gresleri «Quid agam?» (¿Qué hacer?) es el manifiesto de la impotencia del 

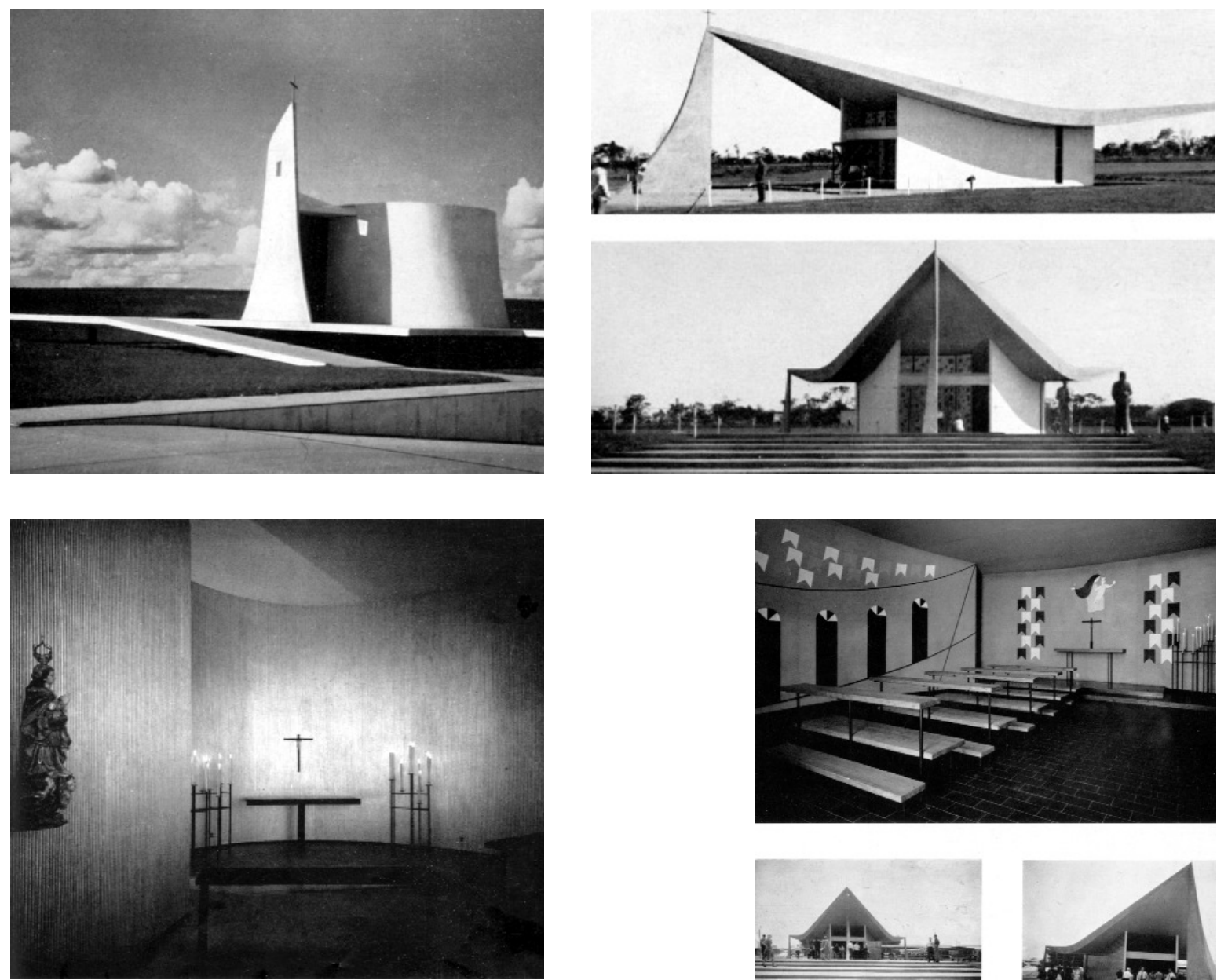
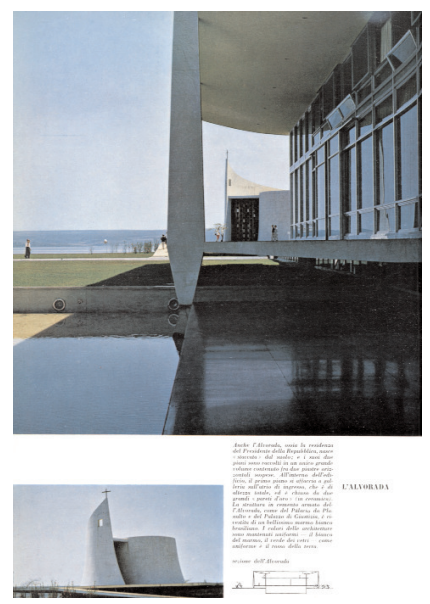

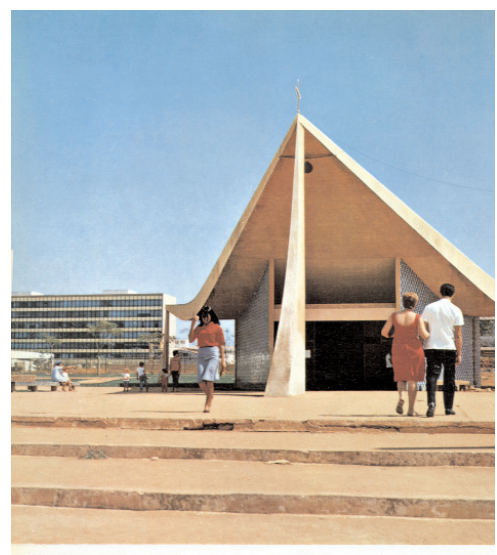

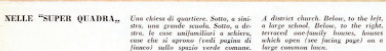

Fig. 12. Oscar Niemeyer, capilla presidencial de la Alvorada (a, c, e), 1956/57 e iglesia parroquial de

Nossa Senhora de Fátima en una de las

Supercuadras (b, d, f), 1958, Brasilia (Brasil).

L'Architettura. Cronache e storia 51 (1960) (a, b);

Papadaki 1961 (c, d); Domus 434 (1966) (e, f). 
debate arquitectónico y urbanístico occidental frente al drama de América Latina, que pone en crisis «el privilegio, la comodidad y el mito de nuestras tan indispensables profesiones, que queremos que sean la excusa para darle un propósito a nuestro vivir cotidiano». Se podrá comprender «que sería verdaderamente un lujo consumar nuestra vida» en cuestiones ahora consideradas marginales (la tutela de los centros históricos, los planos reguladores, los parques públicos, la contaminación de las aguas): América Latina ofrece «un extraordinario ejemplo de vida comunitaria y de fraternidad humana que se superpone de modo estridente a la planificación importada desde Europa, impuesta por la oligarquía y limitada siempre a visiones parciales del problema y, por tanto, causante de la decadencia de la consciencia comunitaria» (Gresleri 1968, 3). Comentando una noticia de las revoluciones en curso, la redacción se pregunta: «¿Cuales son los instrumentos que justifican y vuelven válida nuestra profesión en países donde el alimento cotidiano es un lujo y la autopista un privilegio de una minoría numéricamente insignificante?» (Bouin 68, 30).

La sensación de impotencia se asocia con la de vergüenza por la degradación social y urbanística de los suburbios en las metrópolis latinoamericanas, como denuncia Sergio Cammelli a propósito de su experiencia en el barrio de los alagados [ocultos, sumergidos; lit. inundados, ndt.] de Salvador de Bahía: «Yo soy responsable, junto con mis padres, de esta situación [...] estoy avergonzado de existir» (Camelli 1968, 8).

Además de los temas pastorales, sociales y políticos, es difícil identificar temas arquitectónicos: en la sección Urbanistica e architettura in America Latina se presentan algunas reflexiones sobre las barriadas peruanas - según los autores, preferibles a los modernos alojamientos estatales «porque se convierten en comunidades de personas que tienden constantemente a su propia redención» (Camelli 1968, 49)—, sobre los pueblos del nuevo México (¡el único artículo en el que se habla de una iglesia!) y el Movimiento Moderno en Brasil y Buenos Aires (Bracco 1968; Segre 1968) ${ }^{18}$.

En síntesis, el descubrimiento de América Latina supone la autoanulación del debate sobre la arquitectura litúrgica, o al menos su redimensionamiento ideológico. De hecho, las publicaciones eclesiales no se harán cargo de la publicidad o de la profundización en el contexto eclesial de las iglesias más conocidas, dejando a las publicaciones técnicas una interpretación exclusiva- mente formalista o ideológica. Aparecerán en las revistas y libros de arquitectura las tres iglesias de Niemeyer en Brasilia — capilla presidencial de la Alvorada, iglesia parroquial de Nuestra Señora de Fátima en una de las Supermanzanas, y la catedral (Fig. 12) -, cuya diversidad de escala, poética y función no serán nunca subrayadas desde el punto de vista eclesial. Las extravagantes estructuras de Félix Candela para Enrique de la Mora y Fernando López Carmona (Moreyra y Billington 2008; Savorra 2013), las experiencias de Claudio Caveri y Eduardo Ellis (Saggi sull'Argentina 1964; Peani 1964; Bullrich 1970), de los benedictinos Martín Correa y Gabriel Guarda (Bullrich 1970), o la investigación tecnológica de Eladio Dieste (Dieste 1962; Bullrich 1970; Daguerre 2003) (Fig. 13) son presentadas como si fueran episodios de una América Latina diversa de la que estudiaba Chiesa e Quartiere.

El impacto de este silencio eclesial — junto con la teología de la secularización y la contestación estudiantil y obrera surgida en 1968 - será decisivo para la cultura arquitectónica italiana y la investigación sobre las iglesias considerará con creciente escepticismo los intentos de utilizar la iglesia como medio expresivo del cristianismo. Durante los años setenta, la creación de espacios de culto quedará encomendada casi de modo absoluto a la espontaneidad de la vida comunitaria, con éxitos irrelevantes o, genéricamente, tercermundistas.

Los grandes iconos estructurales latinoamericanos volverán al debate sólo con el retorno a lo monumental en la Europa descristianizada de los años ochenta, en donde la nueva evangelización volverá a reclamar un papel importante para la expresión identitaria cristiana en las metrópolis secularizadas (Longhi 2013).

\section{IMÁGENES E IMAGINARIOS}

Sería difícil identificar citas exactas de las experiencias latinoamericanas en Italia: las cuatro o cinco iglesias más conocidas se convirtieron en iconos casi ahistóricos y atópicos, ciertamente no como emblemas de la espiritualidad de un continente latino y católico, sino como expedientes de un inmediato impacto sacral, prescindiendo de su condición originaria. Si nos tuviéramos que limitar a una valoración purovisualista, serían innumerables las obras inspiradas - de un modo probablemente inconsciente - en los paraboloides hiperbólicos de Candela, en las superficies sinuosas de Dieste, en las costillas de la catedral de Brasilia o en las curvas en 

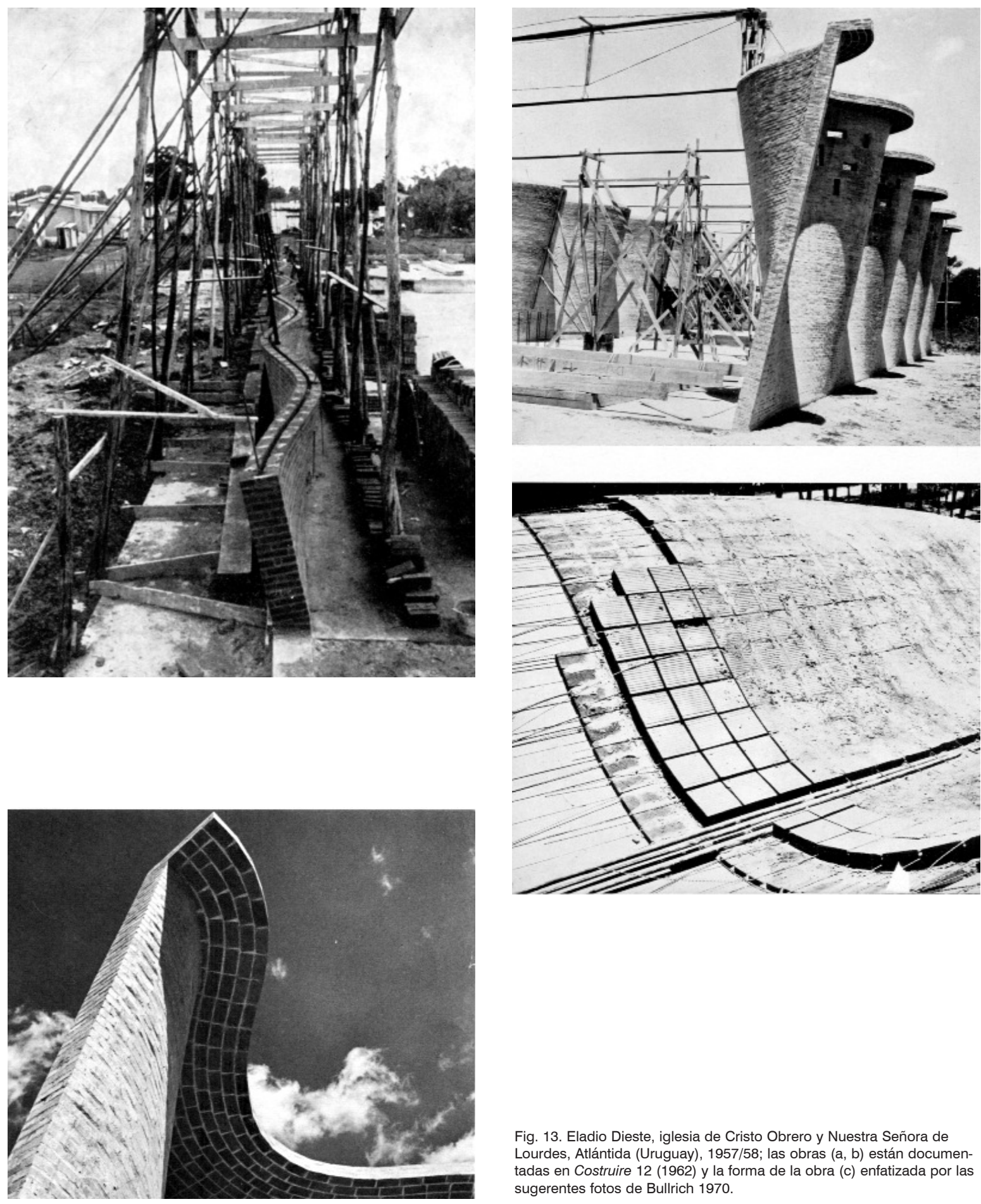

Fig. 13. Eladio Dieste, iglesia de Cristo Obrero y Nuestra Señora de Lourdes, Atlántida (Uruguay), 1957/58; las obras (a, b) están documentadas en Costruire 12 (1962) y la forma de la obra (c) enfatizada por las sugerentes fotos de Bullrich 1970. 
Pampulha de Niemeyer, pero no sería correcto críticamente recorrer esta vía de lectura solamente formalista.

Concluyamos con una referencia reciente a una sola obra, que evoca figurativamente la imagen de la iglesia de Pampulha. Setenta años después de su realización y condena eclesiástica, el perfil ondulado de las bóvedas de San Francisco ha sido recogido - casi por una némesis histórica - justo en el corazón de la catolicidad, en el proyecto del Studio Anselmi para la iglesia de San Pío da Pietrelcina (Fig. 14), vencedor del concurso convocado por el vicariato de Roma en $2005^{19}$. Si bien los dos edificios no comparten nexos funcionales o tipológicos $-\mathrm{y}$ si bien cualquier acusación de copia o plagio aparece como poco fundada y no documentable (Marandola 2011 y 2012) - una mirada distraída no podrá dejar de notar la asonancia figurativa entre el perfil laicamente incrustado en el contexto natural brasileño y el manto trinitario extendido sobre la iglesia romana: un signo ya incorporado al imaginario arquitectónico compartido, convertido en símbolo del rescate y de la nueva identidad de una de las más grotescas y anónimas periferias romanas (Anselmi 2013).

\section{NOTAS}

(1) Sobre la cultura arquitectónica eclesial italiana en las años del Concilio puede verse: Gabetti 2000; Benedetti 2000; Della Longa 2005; Dianich 2008; Longhi y Tosco 2010; Santi 2012.

(2) En el momento de la apertura del Concilio en 1962, los obispos de América Central y Meridional eran 620 (sobre 2540, es decir, el 24\%), frente a los todavía 423 italianos; en conjunto, en el Vaticano II participaron 346 obispos hispanoamericanos y 171 brasileños, cerca del 20\% de la asamblea (Mezzadri 2015, 14-15 y 183).

(3) «Gaudium et spes, luctus et angor hominum huius temporis, pauperum praesertim et quorumvis afflictorum, gaudium sunt et spes, luctus et angor etiam Christi discipulorum, nihilque vere humanum invenitur, quod in corde eorum non resonet». («Los gozos y las esperanzas, las tristezas y las angustias de los hombres de nuestro tiempo, sobre todo de los pobres y de cuantos sufren, son a la vez gozos y esperanzas, tristezas y angustias de los discípulos de Cristo. Nada hay verdaderamente humano que no encuentre eco en su corazón».) Gaudium et Spes, 1.

(4) Subraya cómo el proyecto había sabido «lograr injertar una sana sensibilidad moderna sobre una copia antigua» («compiere l'innesto sulla copia antica in uno spirito di sana sensibilità moderna»). (Il riattamento 1953, 66).

(5) Precisa Apollonj-Ghetti que: 1) el proyecto litúrgico fue realizado por el estudio de Giuseppe Saverio Giacomini (italiano con estudio en Sao Paolo); 2) la elección de los artistas corresponde también al mismo Giacomini, tras escuchar el parecer de Apollonj en calidad de arquitecto del proyecto; 3 ) el representante legal de la Legiao de Sao Paulo pro Catedral es el doctor Deoclecio Redig de Campos (historiador del arte activo en las instituciones vaticanas), requerido para esa labor por el cardenal Carlos Carmelo de Vasconcellos Motta.

(6) Escultores Alfredo Biagini, Eugenio de Courten, Venanzio Crocetti, Toni Fiedler y Francesco Nagni; pintores Marcello Avenali, Francesco Benicivenga, Giovanni Haynal, Max Ingrand, Lorenzo Micheli Gigotti y Gilda Nagni.

(7) La iglesia matriz del Bom Jesus da Cana Verde, comenzada en 1928 bajo la dirección del arquitecto italiano Júlio Latini, realizada por el también italiano Carlos Zamboni, fue concluida en 1953. En su interior destacan numerosas pinturas de Cándido Portinari (1903/62), brasileño hijo de emigrantes venecianos.

(8) Anota el redactor: «El clima de América Latina y el mosaico de las razas humanas que constituyen su población han condicionado el carácter de la nueva arquitectura sacra. En los tiempos pasados, estos países no sólo no habían atraído a los grandes artistas religiosos europeos; sino que fueron víctimas de la oferta, por parte de Europa, de obras de arte comercial de poca cualidad. Sólo tras la Primera Guerra Mundial se formaron lentamente algunos pequeños pero sólidos círculos interesados en los nuevos problemas de la liturgia y del arte sacro; el primer resultado de este esfuerzo de buena voluntad fue la iglesia de Monterrey (1929/46, arq. Roberto Wakeham) [sic.] e inmediatamente después la de Pampulha en Brasil (1943, arq. Oscar Niemeyer). Tras muchas resistencias negativas, América del Sur consigue tener óptimas escuelas de arquitectura; artistas cristianos se reunieron en Lima (Perú), en Santiago de Chile, en Uruguay y en otros países; hoy existen diversos centros creativos para la proyectación de iglesias modernas. El autor de la investigación [editada por Das Münster], el profesor Adolfo Winternitz, de Lima, ilustra muchos ejemplos de realizaciones recientes y proyectos». («Il clima dell'America Latina e il mosaico 

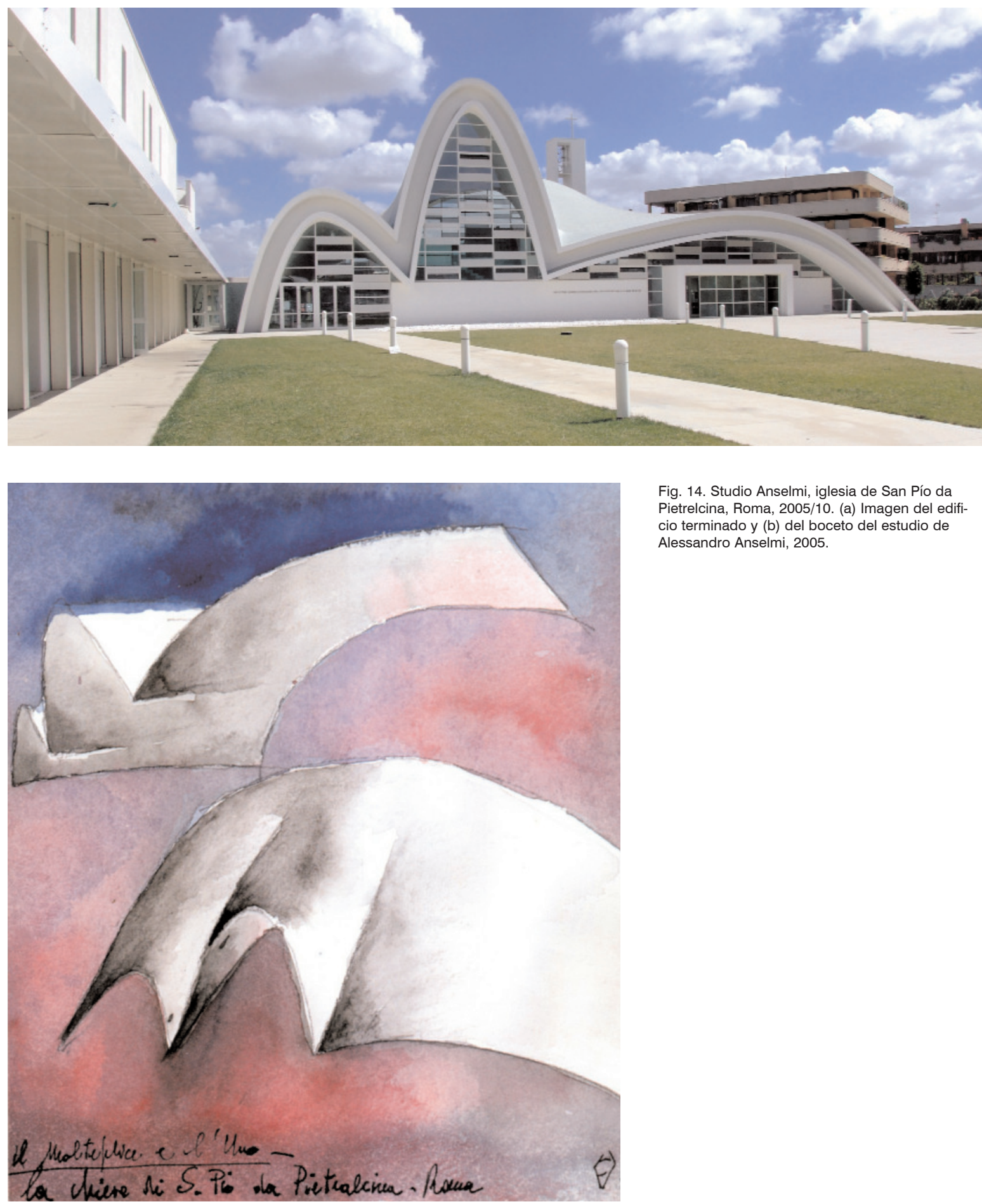

Fig. 14. Studio Anselmi, iglesia de San Pío da Pietrelcina, Roma, 2005/10. (a) Imagen del edificio terminado y (b) del boceto del estudio de Alessandro Anselmi, 2005. 
delle razze umane che ne costituiscono la popolazione hanno condizionato il carattere delle nuove architetture sacre. Nei tempi passati questi paesi non solo non avevano attirato i grandi artisti religiosi europei; ma anzi furono vittime della fornitura, da parte dell'Europa, di opere d'arte commerciali di cattiva qualità. Solo dopo la prima guerra mondiale vi si formarono lentamente dei piccoli ma solidi circoli interessati ai nuovi problemi della liturgia e dell'arte sacra; il primo risultato di questo sforzo di buona volontà fu la chiesa di Monterrey (1929-1946, arch. Roberto Wakeham) e subito dopo quella di Pampulha nel Brasile (1943, arch. Oscar Niemeyer). Dopo molte resistenze negative l'America del Sud riusci ad avere ottime scuole d'architettura; artisti cristiani si riunirono a Lima nel Perù, a Santiago del Cile, in Uruguay e in altri paesi; oggi vi sono diversi centri creativi per la progettazione delle chiese moderne. L'autore dell'inchiesta, il professore Adolfo Winternitz di Lima, illustra molti esempi di realizzazioni recenti e progetti.»)

La nota está ilustrada por fotografías de las iglesias de la Virgen de la Soledad del Altillo y de San Antonio de las Huertas, en Ciudad de México (Enrique de la Mora y Palomar). La autoría de la iglesia de Monterrey que se cita no corresponde al arquitecto peruano Roberto Wakeham, sino al mismo Enrique de la Mora.

(9) El crítico habla de la «umilissima casa di Dio che vogliamo ricordare qui, in questa rubrica, nella quale si parla di grandiose cattedrali, formulando il voto che essa costituisca il seme di una grande Cristianità: perché non è l'imponenza delle proporzioni o la ricchezza decorativa a far la gloria di una chiesa, ma la presenza sul suo altare - ricco o modesto che sia-di Gesù Eucaristico».

(10) «La chiesa in questione, in quanto non è un'opera d'arte sacra, non può ospitare il Sacramento dell'Altare né essere adibita al culto, e sapientissima è stata la decisione del Vescovo di non consacrarla. Ma poiché essa è indubbiamente un'opera d'arte, ottimamente ha fatto il Governo brasiliano a salvarla dall'inconsulto vandalismo del Sindaco ed a conservarla all'ammirazione dei turisti che vi accorrono, ci dicono, numerosissimi. Perché non si è fatto altrettanto - così da parte dell'autorità ecclesiastica come di quella civile- per le cappelle di Vence e di Ronchamps [sic], eccellenti architetture e pessime chiese?».
(11) La bibliografía al final del artículo de Sammartini $(1961,42)$ cita una abundante serie de documentos bibliográficos internacionales: Progressive Architecture, junio 1954; Ars et Architecture, enero 1955; Architectural Forum, noviembre 1955; Arquitectura México, diciembre 1955; L'Architettura, febrero 1956; L'Architecture d'Aujourd'hui, marzo 1956; Architectural Record, julio-agosto 1958; The Architectural Review, noviembre 1958.

(12) «Invece di partire dalla funzione per creare un'architettura, l'architetto De La Mora sembra al contrario partire da volumi in cui ha iscritto le differenti attività previste dal programma di una chiesa. Dissociando la forma dalla funzione, De La Mora sembra cadere in un manierismo ossia sembra dedicarsi più alla ricerca di forme sorprendenti che convincenti».

(13) «Certe forme curvilinee sono interessanti ma si avvicinano ad una ossessione maniaca: sono simbolismo e non il risultato di un volume nato dall'esperienza di un essere come occupante».

(14) «Tutto ciò, tuttavia, non può autorizzare nessuno a considerare chiuso il capitolo della architettura sacra monumentale. Non c'è stata nessuna condanna e non c'è stato, da parte della Chiesa, nessun consiglio per considerarla come una manifestazione esclusiva del passato. L'esempio di quel Vescovo del Brasile, che in mezzo alla immane miseria e alla ignoranza dei fedeli, ha creduto bene di non continuare la costruzione di una cattedrale, per andare incontro alla liberazione dalla fame e alle esigenze della istruzione dei poveri, ci ha commosso e ci ha trovato consenzienti. Per costruire cattedrali c'è sempre tempo e, in certe contingenze, si rende più onore a Dio on la carità e con le chiese-capanne che con sontuosi edifici di culto. Ma l'esempio non sarebbe più valido se si pretendesse che a Brasilia non fosse costruita anche una cattedrale degna di quella nuova e splendida capitale».

(15) «Non abbiamo più bisogno di nuove forme architettoniche, ma di nuove 'soluzioni'; il concilio ha chiuso un periodo, per tutti. Oggi non esiste tanto il problema di una architettura sacra, quanto il problema di una visione cristiana dell'architettura e del ruolo che essa copre nella società moderna, così come non esiste un problema di arte sacra, ma quello di riconoscere un attributo di sacralità all'arte, proprio per la sua qualità medianica circa i messaggi dello spirito!». 

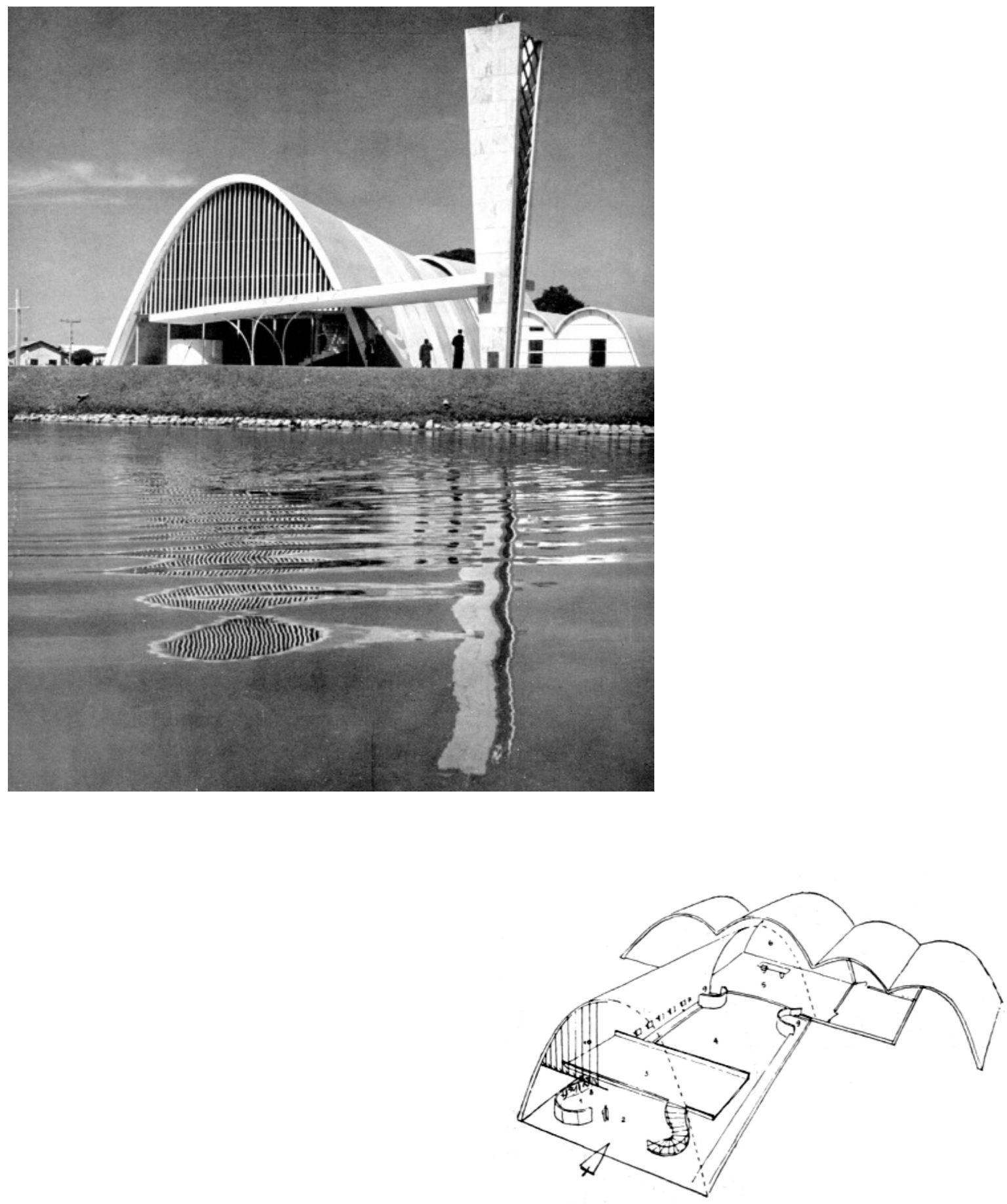

Fig. 15. Oscar Niemeyer, iglesia de San Francisco de Asís en Pampulha (Brasil), tal como fue publicada por Papadaki en 1961. 
(16) La diócesis de Río de Janeiro, instituida en 1676, tuvo diversas sedes provisionales hasta el proyecto de 1749, abandonado tras la llegada de la familia real portuguesa en 1808. Tras la institución de la República en 1889, sólo en 1963 el gobierno del Estado reconoce una indemnización a la diócesis, ofreciendo el terreno para la construcción del edificio, cuya primera piedra fue bendecida el 20 de enero de 1964. Dirección y coordinación del proyecto: mons. Ivo Antonio Calliari; obras de arte sacro: mons. Guilherme Schubert; construcción: prof. Carlos Alberto del Castillo; arquitectura, prof. Edgard de Oliveira Fonseca.

(17) «Cosa si è costruito all'Aparecida? Una chiesa al cui confronto impallidiscono per altezza le strutture delle terme di Diocleziano, affiancata da una torre in cemento armato alta $60 \mathrm{~m}$ ! (Ignoriamo la qualità, la quantità dei «marmi» che certamente completeranno l'insieme). Non intendiamo né polemizzare, né criticare un discorso che non può neppure lontanamente essere preso in considerazione e chiamato architettura. $\mathrm{Ci}$ sia consentito essere scandalizzati di questa testimonianza, tra uomini poveri e semplici, le cui abitazioni sono, nell'anno 2000, di fango e di paglia».

(18) El texto está extraído del libro del autor (Bracco 1967), del cual, sin embargo, ha sido eliminado el capítulo central sobre el rol del arquitecto, en el que se hablaba entre otras de las iglesias de Niemeyer (no citadas, por lo tanto, en el artículo).

(19) Proyecto definitivo y de ejecución: 2006/07 (Alessandro Anselmi, Valentino Anselmi, Valerio Palmieri di SAA\&A: Studio di Architettura Anselmi \& Associati); construcción: 2008/10; dedicación: 23 de octubre de 2010.

\section{BIBLIOGRAFÍA}

«Il nuovo centro civico e la chiesa di Puerto

Ordaz». 1958. Chiesa e Quartiere 6:75.

«Il riattamento della cattedrale di San Paolo del

Brasile». 1953. Fede e Arte 3/53:66-76.

«Inchiesta su Brasilia. Sei ? sulla nuova capitale».

1960. L'Architettura. Cronache e storia 51:608-619. «Istituto Internazionale di arte liturgica». 1955.

Fede e Arte 3/55:90.

«L'Aparecida». 1967. Chiesa e Quartiere 43:65.

«La cattedrale di Rio de Janeiro». 1966. Fede e

Arte 1/66:58-69.
«Notiziario sudamericano». 1954. Fede e Arte

11/54:361-162.

«Notiziario». 1959. Fede e Arte 2/59:236-237.

«Notiziario». 1953. Fede e Arte 5/53:155.

«Rassegna della stampa periodica internazionale». 1953. Fede e Arte 12/53:381.

«Saggi sull'Argentina». 1964. Casabella 285; número monográfico.

«Strutture e strutturalismo. Una lettera di Felix Candela». 1959. Casabella 232:48-49.

«Una chiesa al Messico». 1955. Domus 308:2.

Alfano, Mario. 1966. «L'architettura sacra dalla seconda metà del Settecento ad oggi». Fede e Arte 2/66:290-337.

Anselmi, Alessandro. 2013. «Una chiesa di quartiere». En Chiese della periferia romana 2000-2013. Dal grande Giubileo all'anno costantiniano, editado por Marco Petreschi y Nilda Valentin, 226-228. Roma: Electa.

Argenti, Maria. 2010. Alessandro Anselmi. Roma: Edilstampa.

Benedetti, Sandro. 2000. L'architettura delle chiese contemporanee. Il caso italiano. Milán: Jaca Book.

Bouin, Paul. 1968. «Violenza e tensione in America Latina». Chiesa e Quartiere 46/47:30-38.

Bracco Baratta, Gemma. 1994. Voz «Fallani, Giovanni». En Dizionario Biografico degli Italiani, vol. 44, 462-465. Roma: Istituto della Enciclopedia Italiana.

Bracco, Sergio. 1967. L'architettura moderna in Brasile. Bolonia: Cappelli.

Bracco, Sergio. 1968. «Brasile: o dell'importazione del Movimento Moderno in America Latina». Chiesa e Quartiere 46/47:56-68.

Bravo, Francisco. 1967. «L'esperienza di S. Miguelito». Chiesa e Quartiere 43:34-37.

Bullrich, Francisco Jorge. 1964. Arquitectura argentina contemporánea. Buenos Aires: Nueva Visión.

Bullrich, Francisco Jorge. 1969. Arquitectura Latinoamericana. 1930-1970. Buenos Aires: Sudamericana.

Bullrich, Francisco Jorge. 1970. Orientamenti nuovi nell'architettura dell'America Latina. Milán: Electa.

Câmara, Jaime de Barros. 1959. «Arte liturgica». Fede e Arte 4/59:362-371. 
Cammelli, Sergio. 1968. «America America!»

Chiesa e Quartiere 46/47:8-12.

Caruso, Paolo. 1967. «Per secoli noi europei».

Chiesa e Quartiere 43:4-6.

Casati, Cesare. 1966. «Immagini di Brasilia 1966». Domus 434:2-24.

Chenis, Carlo. 2002. «Natura, competenze, organizzazione e attività della Pontificia Commissione per i Beni Culturali della Chiesa». En Enchiridion dei beni culturali della Chiesa. Documenti ufficiali della Pontificia Commissione per i Beni Culturali della Chiesa, 17-85. Bolonia: EDB.

Concilio Vaticano II. 1965. Constitución Gaudium et Spes, 7 de diciembre. Consultado el 17/11/2016, www.vatican.va/archive/hist_councils/ii_vatican_coun cil/documents/vat-ii_const_19651207_gaudium-etspes_sp.html.

Daguerre. Mercedes, ed. 2003. Eladio Dieste. 1917-2000. Milán: Electa.

De Marchis, Daniele. 2013. «Introduzione». En L'Archivio della Commissione Centrale per l'Arte Sacra in Italia. Inventario, editado por Daniele De Marchis, 1-88. Ciudad del Vaticano: Archivio Segreto Vaticano (Collettanea Archivi Vaticani, 92).

Della Longa, Giorgio. 2005. «L'architettura di chiese in Italia nel XX secolo». En Architettura e Liturgia nel Novecento. Esperienze europee a confronto, editado por Giorgio Della Longa, Antonio Marchesi y Massimiliano Valdinoci, 97-112. Rovereto: Nicolodi.

Dianich, Severino. 2008. La chiesa e le sue chiese. Teologia e architettura. Cinisello Balsamo: San Paolo.

Dieste, Eladio. 1962. «La chiesa di Atlantida in Uruguay». Costruire 12:39-46.

Fernández-Cobián, Esteban. 2013. «Aalto, Lercaro y el problema de la participation activa de los fieles». En Escritos sobre arquitectura religiosa contemporánea, 164-189. Buenos Aires: Diseño.

Fitzpatrick, Joseph. 1966. «La parrocchia del futuro». Chiesa e Quartiere 39:40-44.

Freixa Janariz, Jaume. 1979. Josep Lluis Sert.

Barcelona: Gustavo Gili.

Gabetti, Roberto. 2000. Chiese per il nostro tempo.

Come costruirle, come rinnovarle. Leumann: ElleDiCi.

Gresleri, Giuliano. 1968. «Quid agam?». Chiesa e

Quartiere 46/47:2-3.

Gresleri, Glauco, Maria Beatrice Bettazzi y Giuliano Gresleri, eds. 2004. Chiesa e Quartiere.
Storia di una rivista e di un movimento per l'architettura a Bologna. Bolonia: Compositori.

Gresleri, Glauco. 1966. «Una età nuova». Chiesa e Quartiere 37:8-9.

Gresleri, Glauco. 1990. «Architettura sacra in Italia dal Dopoguerra al Concilio Vaticano II». En Il Sacro. L'architettura sacra oggi, 181-191. Rimini: Stauròs Internazionale/Il Cerchio.

Italicus. 1965. «Arte e liturgia». Fede e Arte 1/65:96-101.

Longhi, Andrea, y Carlo Tosco. 2010. Architettura, Chiesa e società in Italia. (1948-1978). Roma: Studium.

Longhi, Andrea. 2010. «Nuove chiese in contesti non cristiani». En Chiesa e città, actas del VII Convegno Liturgico Internazionale (Bose, 4-6 junio 2009), editadas por Goffredo Boselli, 153-178. Magnano: Qiqaion.

Longhi, Andrea. 2013. «Church building beyond church architecture: evangelization and architecture / Construir iglesias más allá de la arquitectura religiosa: evangelización y arquitectura». Actas del Congreso Internacional de Arquitectura Religiosa Contemporánea 3:2-25; consultado el 24/11/2016, www.arquitecturareligiosa.es/index.php/AR/article/view/110.

Manenti, Claudia. 2010. Il cardinale Lercaro e la città contemporanea. Bolonia: Compositori.

Marandola, Marzia. 2011. «Le onde pie di

Malafede». Casabella 798:6-13.

Marandola, Marzia. 2012. «Chiesa di San Pio da Pietrelcina a Malafede-Anselmi \& Associati». Arketipo 69:56-77.

Mezzadri, Luigi. 2015. I vescovi al Concilio. Servi della Parola e Padri della fede. Todi: Tau.

Montini, Renzo U. 1955a. «Notiziario estero». Fede e Arte 8/55:256.

Montini, Renzo U. 1955b. «Notiziario estero». Fede e Arte 10/55:313-314.

Moreyra Garlock, Maria E., y David P. Billington, 2008. Félix Candela. Engineer, Builder, Structural Artist. New Haven/London: Princeton University Art Museum/Yale University Press.

Nicoletti, Manfredi. 1957. «Incontro con Felix Candela». L'Architettura. Cronache e Storia 16:724-729.

Oswald, Carlos. 1953. «L'arte sacra in Brasile e l'attività della 'Sociedade Brasileira de Arte Cristà'». Fede e Arte 3/53:89-90. 
Oswald, Carlos. 1954a. «Arte sacra contemporanea in Brasile». Fede e Arte 6/54:179-186.

Oswald, Carlos. 1954b. «L'artista cristiano». Fede e Arte 11/54:360-361.

Papadaki, Stamo. 1961. Oscar Niemeyer. Milán: Il Saggiatore.

Peani, Gian Lodovico. 1964. «La architettura moderna in Argentina». Casabella 285:3-43.

Pighin, Bruno Fabio. 2015. «Celso Costantini nell'arte sacra del XX secolo». Arte Cristiana 886:9-17. 17:38.

Redazione. 1961. «Premessa». Chiesa e Quartiere 45:II.

Redazione. 1968. «Premessa». Chiesa e Quartiere

Rovira Gimeno, Josep Maria. 2000. José Luis Sert 1901-1983. Milán: Electa.

Sammartini, Tudy. 1961. «Quattro chiese dell'architetto Enrico De la Mora y Palomar con strutture dell'ingegnere Felix Candela». Chiesa e Quartiere 17:38-62.

Santi, Giancarlo. 2012. L'architettura delle chiese in Italia. Il dibattito, i riferimenti, i temi. Magnano: Qiqajon.

Savorra, Massimiliano. 2013. La forma e la struttura. Félix Candela, gli scritti. Milán: Electa.
Segre, Roberto. 1968. «Un esempio catalizzante: Buenos Aires e il piano di Corbu». Chiesa e Quartiere 46/47:68-73.

Spade, Rupert. 1971. Oscar Niemeyer. New York: Simon and Schuster.

\section{PROCEDENCIA DE LAS ILUSTRACIONES}

Fig. 01. Fede e Arte 3/53 (1953).

Fig. 02. Chiesa e Quartiere 6 (1958).

Fig. 03 y 07. Chiesa e Quartiere 17 (1961).

Fig. 04. Domus 308 (1955).

Fig. 05. L'Architettura. Cronache e Storia 16 (1957).

Fig. 06. Casabella 232 (1959).

Fig. 08. Fede e Arte 1/66 (1966).

Fig. 09. (a) L'Architettura. Cronache e Storia 51 (1960); (b) Domus 434 (1966).

Fig. 10. Chiesa e Quartiere 43 (1967).

Fig. 11. Chiesa e Quartiere 46/47 (1968).

Fig. 12. (a, b) L'Architettura. Cronache e storia 51 (1960); (c, d) Papadaki 1961; (e, f) Domus 434 (1966).

Fig. 13. (a, b) Costruire 12 (1962); (c) Bullrich 1970.

Fig. 14. Argenti 2010.

Fig. 15. Papadaki 1961. 